\title{
Basal antero-septal anomalous papillary muscle in hypertrophic obstructive cardiomyopathy
}

George O Angheloiu" ${ }^{1 *}$, Jason W Vokes ${ }^{1}$, Valerie A Pearce ${ }^{1}$, Kathy L DeLong ${ }^{1}$, Bryan E Jacobson',

Sharon R Hallstrom', Bobby Byerly ${ }^{1}$, Sally McClain ${ }^{1}$, Robert W Biederman ${ }^{2}$

From 18th Annual SCMR Scientific Sessions

Nice, France. 4-7 February 2015

\section{Background}

We report the presence of an anomalous papillary muscle inserting into the basal antero-septum in patients with hypertrophic obstructive cardiomyopathy (HOCM) investigated by means of cardiac MRI.

\section{Methods}

9 consecutive patients with HOCM and 13 age- and gender-matched controls without this condition were interrogated using a Siemens Espree MRI machine. A diagnosis of HOCM was established on the basis of asymmetric antero-septal left ventricle hypertrophy and systolic anterior motion of the mitral apparatus.

\section{Results}

$100 \%$ of HOCM patients and $62 \%(\mathrm{n}=8, \mathrm{P}=0.05)$ of controls demonstrated an anomalous papillary muscle connecting the left ventricle basal antero-septum with the apex, noticeable on a long axis view acquired on an SSFP sequence. This particular structure contracts during during

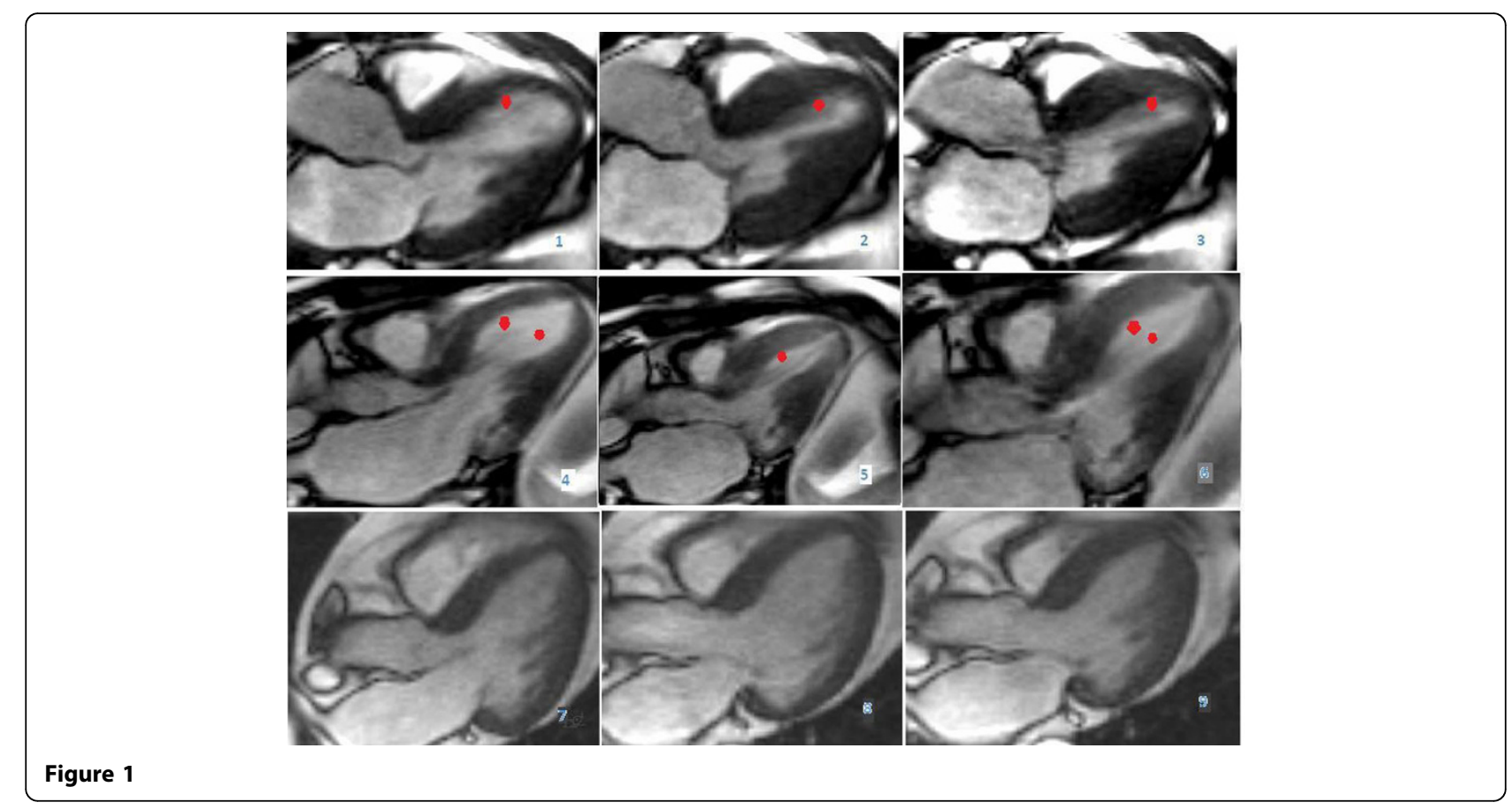

${ }^{1}$ Cardiology, Penn Highlands, Dubois, PA, Dubois, PA, USA

Full list of author information is available at the end of the article

(c) 2015 Angheloiu et al; licensee BioMed Central Ltd. This is an Open Access article distributed under the terms of the Creative Commons Attribution License (http://creativecommons.org/licenses/by/4.0), which permits unrestricted use, distribution, and 
systole as seen in Figure 1 in panels 1 and 4 (diastole), 2 and 5 (mid-systole) and 3 and 6 (end-systole) in two HOCM patients (panels 1-3 and 4-6 respectively). The papillary muscle was not present in panels 7-9 of one control subject. A prominent and a moderate systolic anterior motion of the mitral apparatus are seen in panels 1-3 and 4-6 respectively.

\section{Conclusions}

An anomalous papillary muscle connecting the basal antero-septum with the left ventricular apex and contracting during systole is more commonly seen in HOCM patients than in controls. Further larger studies are needed to elucidate the importance of this anatomical finding in the physiology of left ventricle outflow tract obstruction.

\section{Authors' details}

${ }^{1}$ Cardiology, Penn Highlands, Dubois, PA, Dubois, PA, USA. ${ }^{2}$ Allegheny

General Hospital, Pittsburgh, PA, USA.

Published: 3 February 2015 